\title{
Outcome of Infants Younger Than 1 Year With Acute Lymphoblastic Leukemia Treated With the Interfant-06 Protocol: Results From an International Phase III Randomized Study
}

Rob Pieters, MD, PhD, MSc ${ }^{1,2}$; Paola De Lorenzo, PhD³; Philip Ancliffe, MD4; Luis Alberto Aversa, MD5; Benoit Brethon, MD ${ }^{6}$; Andrea Biondi, MD ${ }^{3,7,8}$; Myriam Campbell, MD ; Gabriele Escherich, MD ${ }^{10}$; Alina Ferster, MD ${ }^{11}$; Rebecca A Gardner, MD ${ }^{12}$; Rishi Sury Kotecha, MB ChB, PhD ${ }^{13,14}$; Birgitte Lausen, MD, PhD ${ }^{15}$; Chi Kong Li, MD ${ }^{16}$; Franco Locatelli, MD, PhD ${ }^{3,7,8}$; Andishe Attarbaschi, MD ${ }^{17}$; Christina Peters, MD ${ }^{18}$; Jeffrey E. Rubnitz, MD, PhD ${ }^{19}$; Lewis B. Silverman, MD ${ }^{20}$; Jan Stary, MD ${ }^{21}$; Tomasz Szczepanski, MD, PhD ${ }^{22}$; Ajay Vora, MD ${ }^{4}$; Martin Schrappe, MD, hhD $^{23}$; and Maria Grazia Valsecchi, PhD ${ }^{3}$

PURPOSE Infant acute lymphoblastic leukemia (ALL) is characterized by KMT2A (MLL) gene rearrangements and coexpression of myeloid markers. The Interfant-06 study, comprising 18 national and international study groups, tested whether myeloid-style consolidation chemotherapy is superior to lymphoid style, the role of stemcell transplantation (SCT), and which factors had independent prognostic value.

MATERIALS AND METHODS Three risk groups were defined: low risk (LR): KMT2A germline; high risk (HR): KMT2A-rearranged and older than 6 months with WBC count $300 \times 10^{9} / \mathrm{L}$ or more or a poor prednisone response; and medium risk (MR): all other KMT2A-rearranged cases. Patients in the MR and HR groups were randomly assigned to receive the lymphoid course low-dose cytosine arabinoside [araC], 6-mercaptopurine, cyclophosphamide (IB) or experimental myeloid courses, namely araC, daunorubicin, etoposide (ADE) and mitoxantrone, araC, etoposide (MAE).

RESULTS A total of 651 infants were included, with 6-year event-free survival (EFS) and overall survival of $46.1 \%$ (SE, 2.1) and 58.2\% (SE, 2.0). In West European/North American groups, 6-year EFS and overall survival were 49.4\% (SE, 2.5) and 62.1\% (SE, 2.4), which were 10\% to 12\% higher than in other countries. The 6-year probability of disease-free survival was comparable for the randomized arms (ADE+MAE 39.3\% [SE 4.0; $\mathrm{n}=169$ ] $v$ IB 36.8\% [SE, 3.9; $\mathrm{n}=161$ ]; log-rank $P=.47$ ). The 6-year EFS rate of patients in the HR group was $20.9 \%$ (SE, 3.4) with the intention to undergo SCT; only $46 \%$ of them received SCT, because many had early events. KMT2A rearrangement was the strongest prognostic factor for EFS, followed by age, WBC count, and prednisone response.

CONCLUSION Early intensification with postinduction myeloid-type chemotherapy courses did not significantly

ASSOCIATED CONTENT

Data Supplement

Author affiliations and support information (if applicable) appear at the end of this article.

Accepted on May 3, 2019 and published at jco.org on July 8 , 2019: DOI https://doi. org/10.1200/JCO.19. 00261

Clinical trial information: EudraCT 2005-004599-19 and NCT00550992. improve outcome for infant ALL compared with the lymphoid-type course IB. Outcome for infant ALL in Interfant06 did not improve compared with that in Interfant-99.

J Clin Oncol 37. @ 2019 by American Society of Clinical Oncology

\section{INTRODUCTION}

Infant acute lymphoblastic leukemia (ALL) is a rare aggressive type of leukemia. To address relevant treatment questions, large international collaborations are needed. The Interfant group was formed in 1999 and comprises 18 national and international study groups $^{1}$. The KMT2A rearrangement is only present in $1 \%$ to $2 \%$ of older children with ALL but occurs in approximately $75 \%$ of infants with ALL. KMT2A is also rearranged in acute myeloid leukemia (AML) and is therefore also known as mixed-lineage leukemia $(M L L) .{ }^{2}$ Infant ALL occurs in an immature B-cell precursor with frequent coexpression of myeloid markers; is sensitive to cytosine arabinoside (araC), 3,4 a key drug for AML treatment; and can even switch to AML. Therefore, in this randomized Interfant-06 trial, we studied whether consolidation with myeloid-style chemotherapy is superior to lymphoid-style chemotherapy, on the backbone of Interfant chemotherapy. Additional aims were to determine the prognostic relevance of clinical and biologic parameters, establish the role of allogeneic stem-cell transplantation (SCT), and compare the outcome between Interfant06 and Interfant-99. Because Interfant-99 showed outcome differences between the West European countries/North American institutes who initiated 
Interfant (original groups) versus other countries mainly from South America, Eastern Europe, and Asia that joined later, analyses were also performed separately for these two groups. This is an unplanned post hoc comparison, which was decided after consulting the data monitoring committee.

\section{MATERIALS AND METHODS}

\section{Patients and Eligibility Criteria}

The Interfant-06 study was registered with the European Clinical Trials Database (EudraCT 2005-004599-19) and at (ClinicalTrials.gov identifier: NCT00550992). Patients were recruited from February 2006 to July 2016. Individual study groups obtained ethics approval and physicians obtained informed consent from parents. Eligibility criteria were a diagnosis of ALL (except those with a mature B phenotype), age 365 days or younger, and no prior antileukemic therapy other than emergency treatment.

\section{Risk Group Stratification and Treatment}

On the basis of Interfant-99, three risk groups were defined: low risk (LR): KMT2A germline; high risk (HR): presence of a KMT2A-rearrangement and age $<6$ months at diagnosis, with WBC count $300 \times 10^{9} / \mathrm{L}$ or more at diagnosis or a poor prednisone response; and medium risk (MR): comprising all other KMT2A-rearranged patients. Treatment details are shown in the Data Supplement. Chemotherapy was given for 2 years according to Interfant-99. The response to prednisone is defined as good if the leukemic blast cell count per microliter of blood is less than 1,000 and defined as poor if this is equal to or greater than 1,000 . Complete remission (CR) was defined at the end of induction as bone marrow with less than $5 \%$ leukemic cells and regenerating hematopoiesis without evidence of leukemia elsewhere. Patients in the MR and HR groups in CR were eligible for randomized treatment with the standard lymphoid course IB in the control group (low-dose araC, 6-mercaptopurine, cyclophosphamide) versus two experimental myeloid courses, namely araC, daunorubicin, etoposide (ADE) and mitoxantrone, araC, etoposide (MAE). This was followed by mercaptopurine, Ara-C, methotrexate, and asparaginase, and oncovin, cyclofosfamide, thioguanine, AraC, dexamethasone, asparaginase, and (daunorubine; OCTADA[D]) and maintenance therapy. All patients in the HR group were eligible to receive SCT. Patients in the MR group with minimal residual disease (MRD) greater than or equal to $10^{-4}$ at the start of OCTADA(D) were recommended for SCT from June 2009, because the Interfant-99 update showed a dismal outcome for them. ${ }^{5}$

\section{End Points, Randomization, and Statistics}

The randomized study aimed at recruiting 320 patients to have $80 \%$ power to detect a disease-free survival (DFS) difference of $16 \%$ at 3 years (41\% DFS in the control arm; $\alpha=0.05$ ). Randomization was performed by each group, with a centralized Web-based system on the basis of random permuted blocks stratified by participating group and risk group.

DFS, the primary end point, was defined as time from random assignment to relapse, death in continuous complete remission from any cause, or second malignant neoplasm, whichever occurred first. The secondary end point was overall survival (OS), defined as the time from random assignment to death from any cause. Other secondary end points were event-free survival (EFS) and OS for the whole cohort; EFS was defined as time from diagnosis to first failure, including death in induction, resistance to induction therapy (ie, no CR at end of induction), relapse, death in CR from any cause, or second malignant neoplasm, and OS as death from any cause. Final follow-up was updated on December 31, 2017, and the median follow-up time was 5.3 years (range, 0.1 to 11.4 years). In estimating end points, time was censored at last follow-up if no events had been observed.

EFS, DFS, and OS curves were computed using the KaplanMeier estimator and the respective SEs according to the Greenwood formula and compared with the log-rank test. The association of patient characteristics and risk group was assessed with the $\chi^{2}$ test. Cumulative incidence of relapse and death in remission was estimated accounting for competing risks and compared with the Gray test. The impact of prognostic factors on outcome was analyzed using the log-rank test for univariate comparisons, using the Cox model and the Wald test for multivariable analyses comparing the outcome of subgroups identified by each factor and using the Cox model for EFS (single step) and the Wald test for the joint analysis of sex, age at diagnosis, WBC count at diagnosis, CD10 expression, KMT2A status, and prednisone response. All analyses were according to intention to treat. All tests were two sided. All analyses were performed using SAS 9.2.

\section{RESULTS}

\section{Patient Characteristics}

There were 651 infants recruited onto the study: 167 LR (26\%), 320 MR (49\%), and 164 HR (25\%). The CONSORT flow diagram is shown in Figure 1. Patient characteristics are reported in the Data Supplement. Forty-five percent of patients were male. Age distribution at diagnosis was $21 \%$ younger than 3 months, 29\% 3 to 6 months, 27\% 6 to 9 months, and $23 \% 9$ to 12 months. WBC count at diagnosis was $100 \times 10^{9} / \mathrm{L}$ or greater in $53 \%$ of patients and $300 \times 10^{9} / \mathrm{L}$ or greater in $29 \%$. There were 10 infants with T-cell ALL (1.5\%) and 25 with biphenotypic leukemia (3.8\%). Of the 568 B-lineage patients with a known CD10 status, $63 \%$ were $\mathrm{CD}_{10}$. There were 510 patients with evaluable CNS status, of whom $83(16 \%)$ had CNS involvement. KMT2A status was known in 643 patients, of which $74 \%$ were KMT2A rearranged; $44 \%$ had $\mathrm{t}(4 ; 11), 22 \% \mathrm{t}(11 ; 19)$, $11 \% \mathrm{t}(9 ; 11)$, and $23 \%$ had other KMT2A translocations. 


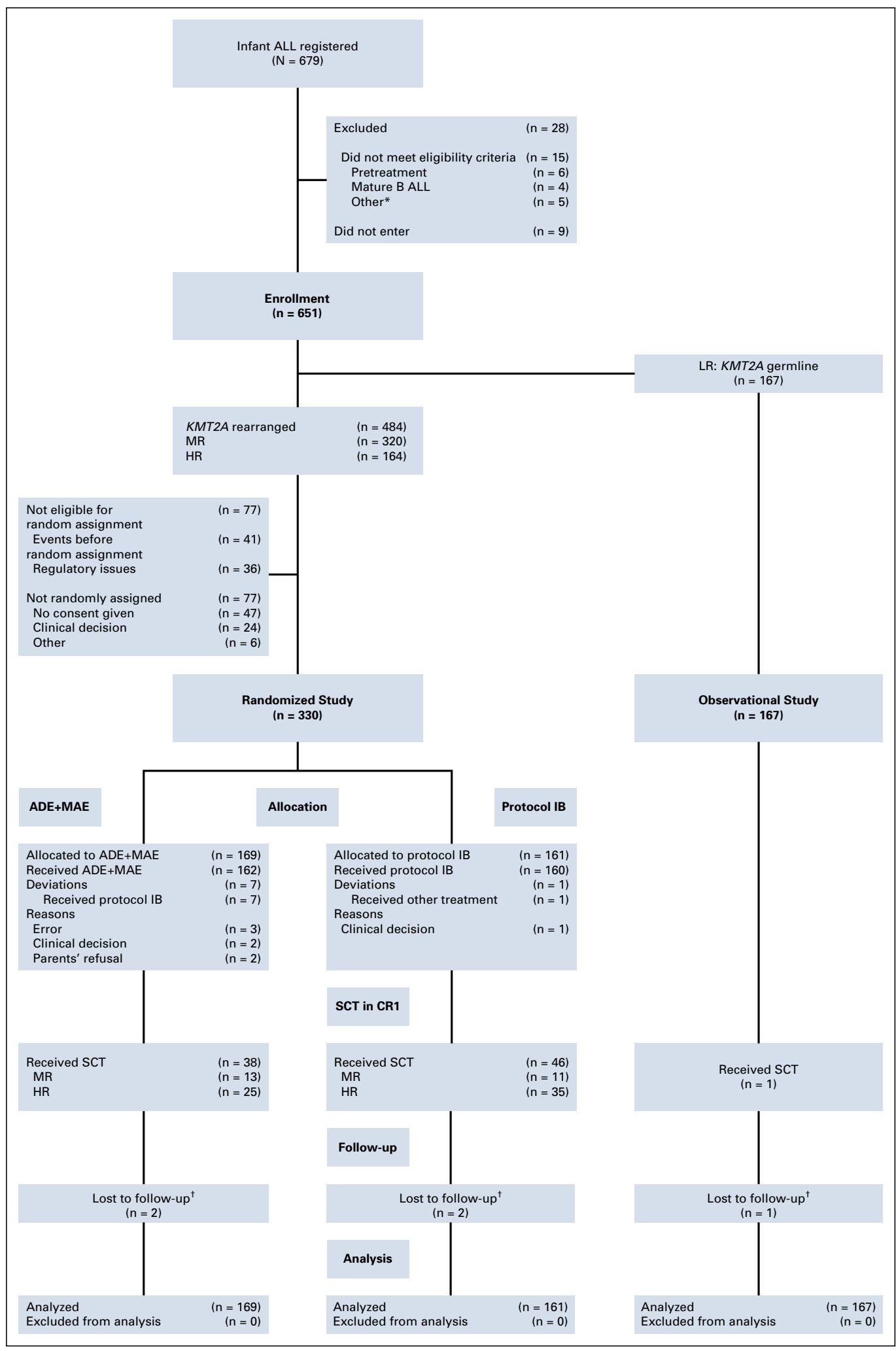

FIG 1. CONSORT diagram. $\left(^{*}\right) K M T 2 A$ status not investigated $(n=2)$, diagnosis and start of treatment outside the Interfant network $(n=2)$, Philadelphia-positive acute lymphoblastic leukemia ( $A L L ; n=1)$. ( $\dagger$ ) Patients lost to follow-up had no follow-up update after December 2015 and less than 4 years of follow-up from diagnosis to last contact (in the analyses, these patients are censored at the date of last contact). araC, cytosine arabinoside; ADE, araC, daunorubicin, etoposide; CR1, first complete remission; HR, high risk; IB, low-dose araC, 6-mercaptopurine, cyclophosphamide; LR, Iow risk; MAE, mitoxantrone, araC, etoposide; MR, medium risk; SCT, stem-cell transplantation. 


\section{Outcome}

The 6-year EFS and OS probabilities (SE) of all 651 patients were $46.1 \%(2.1)$ and $58.2 \%$ (2.0), respectively (Fig 2A). Out of 651 patients, 605 (92.9\%) achieved CR, 24 (3.7\%) died during induction, and 22 (3.4\%) did not achieve CR after induction therapy, of whom 19 died (Data Supplement). There were 244 (37.5\%) relapses, with 66.0\% isolated bone marrow (BM) recurrences, $11.9 \%$ isolated CNS, $1.2 \%$ isolated testicular, $13.1 \%$ combined $\mathrm{BM}$ and
CNS, 2.1\% combined BM and testis, and 5.7\% others. Death in remission occurred in 46 patients (7.1\%); $52 \%$ were due to infection, and $35 \%$ were in patients who underwent SCT. Four patients experienced a second tumor; none of these patients died. Events stratified by risk groups are shown in the Data Supplement. The 6-year EFS for the LR group (KMT2A germline patients) was $73.9 \%$ (3.6) versus $44.5 \%$ (2.9) for the MR and $20.9 \%$ (3.4) for the HR group ( $P<.001$; Fig 2B). The 6-year OS for the LR, MR,

\section{A}

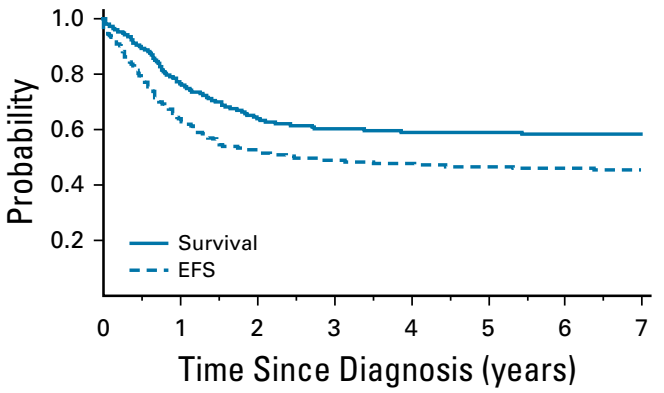

Outcome in Interfant-06 (median follow-up [min-max], years: 5.3 [0.1-11.4])

\begin{tabular}{|c|c|c|c|c|c|c|}
\hline \multirow{2}{*}{$\begin{array}{c}\text { No. } \\
\text { Patients }\end{array}$} & \multirow{2}{*}{\begin{tabular}{|c|} 
No. Events \\
(relapses)
\end{tabular}} & \multicolumn{2}{|c|}{ EFS (SE) } & \multirow{2}{*}{ No. Deaths } & \multicolumn{2}{|c|}{ Survival (SE) } \\
\hline & & 4 Year & 6 Year & & 4 Year & 6 Year \\
\hline 651 & 340 (244) & $47.7(2.0)$ & $46.1(2.1)$ & 258 & $59.1(2.0)$ & $58.2(2.0)$ \\
\hline
\end{tabular}

Outcome in Interfant-99 (update Dec 2007, median follow-up [min-max], years: $4.8[0.1-8.5]$

\begin{tabular}{c|c|c|c|c|c|c}
\multirow{2}{*}{$\begin{array}{c}\text { No. } \\
\text { Patients }\end{array}$} & No. Events & \multicolumn{2}{|c|}{ EFS (SE) } & \multirow{2}{*}{ No. Deaths } & \multicolumn{2}{|c}{ Survival (SE) } \\
\cline { 3 - 4 } \cline { 5 - 6 } & (relapses) & 4 Year & 6 Year & & 4 Year & 6 Year \\
\hline 478 & $249(193)$ & $46.8(2.3)$ & $46.5(2.3)$ & 206 & $56.1(2.4)$ & $53.8(2.5)$
\end{tabular}

C

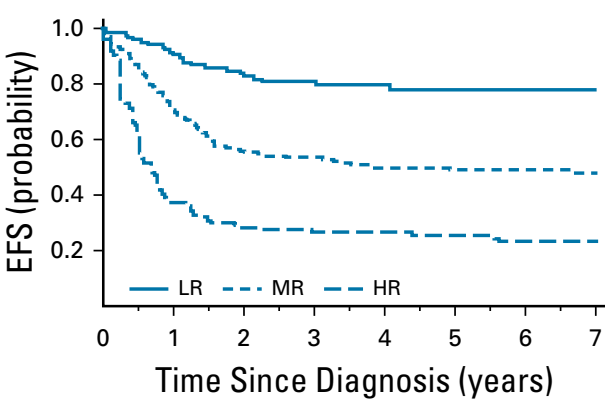

B

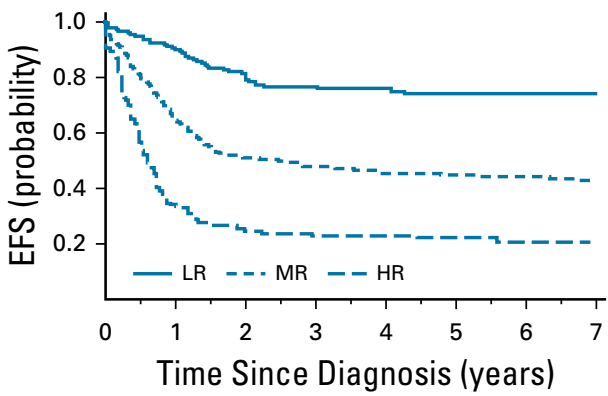

D

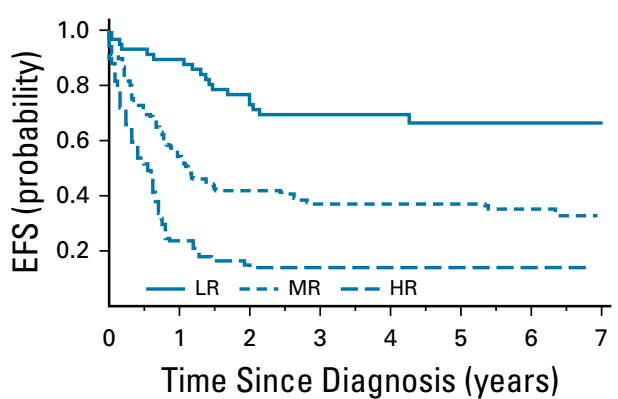

\begin{tabular}{|c|c|c|c|c|c|c|}
\hline \multirow{2}{*}{ Risk Group } & \multirow{2}{*}{$\begin{array}{c}\text { No. } \\
\text { Patients }\end{array}$} & \multirow{2}{*}{ No. Events } & \multicolumn{2}{|c|}{ EFS (SE) } & \multirow{2}{*}{$P$} & \multirow{2}{*}{$\begin{array}{c}\text { Interfant-99 } \\
\text { 4-Year EFS (SE) }\end{array}$} \\
\hline & & & 4 Year & 6 Year & & \\
\hline LR & 112 & 23 & $79.3(4.0)$ & $77.8(4.2)$ & & $74.0(5.3)$ \\
\hline MR & 217 & 106 & $49.8(3.5)$ & $49.0(3.6)$ & $<.001$ & $46.0(3.9)$ \\
\hline HR & 118 & 88 & $26.7(4.1)$ & $23.8(4.2)$ & & $20.8(5.7)$ \\
\hline
\end{tabular}

\begin{tabular}{|c|c|c|c|c|c|c|}
\hline \multirow{2}{*}{ Risk Group } & \multirow{2}{*}{$\begin{array}{c}\text { No. } \\
\text { Patients }\end{array}$} & \multirow{2}{*}{ No. Events } & \multicolumn{2}{|c|}{ EFS (SE) } & \multirow{2}{*}{$\boldsymbol{P}$} & \multirow{2}{*}{$\begin{array}{c}\text { Interfant-99 } \\
\text { 4-Year EFS (SE) }\end{array}$} \\
\hline & & & 4 Year & 6 Year & & \\
\hline LR & 55 & 18 & $68.9(6.3)$ & $66.4(6.5)$ & & 5 patients, 1 relapse \\
\hline MR & 103 & 66 & $37.3(4.9)$ & $35.4(5.0)$ & $<.001$ & $41.0(9.7)$ \\
\hline HR & 46 & 39 & $14.0(5.3)$ & - & & $10.0(11.2)$ \\
\hline
\end{tabular}

FIG 2. (A) Event-free survival (EFS) and overall survival (OS) for all patients in Interfant-06. One second malignant neoplasm (acute myeloid leukemia) occurred at 9.6 years after diagnosis and is not depicted in the curve. (B) EFS by risk group in Interfant-06. (C) EFS by risk group in original study groups (Western European study groups and North American centers that founded Interfant) in Interfant-06. These groups represent the Dutch Childhood Oncology Group, United Kingdom Children Cancer Study Group, French Acute Lymphoblastic Leukemia Study Group, Associazione Italiana Ematologia Oncologia Pediatrica, German Cooperative Study Group for Childhood Acute Lymphoblastic Leukemia, European Organisation for Research and Treatment of Cancer Children Leukemia Group, Nordic Society of Pediatric Hematology/Oncology, Berlin-Frankfurt-Muenster Austria, St Jude Children's Research Hospital, Dana Farber Cancer Institute, Czech Working Group for Pediatric Hematology, and Berlin-Frankfurt-Muenster Group Germany. (D) EFS by risk group in other study groups (study groups that joined the Interfant group later) in Interfant-I06. These groups represent Argentina, Chilean National Pediatric Oncology Group, Australian and New Zealand Childrens Haematology/Oncology Group, The Chinese University of Hong Kong, Polish Pediatric Leukemia/Lymphoma Study Group, and Seattle Children's Hospital and Research Institute. HR, high risk; LR, low risk; MR, medium risk. 
and HR groups was $87.2 \%$ (2.7), $58.1 \%$ (3.0), and $29.9 \%$ (3.7), respectively $(P<.001)$.

\section{Outcome by Randomized Arm}

Of 484 patients in the MR and HR groups, 41 had an event before random assignment (22 deaths, 19 not in remission after induction), and 36 were recruited after random assignment was closed for regulatory reasons in two countries. Seventy-seven (19\%) out of 407 eligible patients were not randomly assigned, mainly because of parental refusal (61\%) or physician's choice (31\%); 330 patients $(81 \%)$ were randomly assigned, 169 to the experimental ADE+MAE arm and 161 to the control IB arm (Fig 1). The randomly assigned patients did not differ according to sex, age, WBC count, immunophenotype, KMT2A status, or response to prednisone (Data Supplement).

The 6-year cumulative incidence of relapse with ADE+MAE was $47.5 \%$ (4.0), which was not significantly lower than the $54.9 \%$ (4.1) with IB (log-rank $P=.11$; Fig 3A). The 6-year cumulative incidence of death in remission was $10.2 \%$ (2.4) with ADE +MAE versus 8.3\% (2.2) with IB (log-rank $P=.51$; Fig 3A). This resulted in no significant difference in 6-year DFS rates when comparing ADE + MAE (39.3\% [4.0]) to IB (36.8\% [3.9]; log-rank $P=.47$; Fig 3B). The study was powered to detect a $16 \%$ difference in DFS at 3-year followup; this was not achieved with 3-year DFS rates of $45.3 \%$ (3.9) with $A D E+M A E$ versus $38.6 \%$ (3.9) with IB. The 6 -year OS for patients treated with ADE+MAE was $54.4 \%$ (4.0) versus $47.1 \%$ (4.2) for those treated with IB ( $P=.27$; Fig 3C). DFS comparison, when adjusted for participating group in a stratified Cox model, confirmed a nonsignificant effect of treatment (hazard ratio, $0.88 ; 95 \% \mathrm{Cl}, 0.66$ to 1.17; $P=.39$ ). A separate Cox model, including a covariate for original versus other countries, showed that the treatment effect was not different in these two groups.

The 6-year DFS was not significantly different between the ADE+MAE arm (49.8\% [5.0]) and IB arm (42.6\% [5.1]; $P=.31$ ) within the MR group (Fig 3D), nor did the 4-year DFS differ within the HR group (25.5\% [5.8] and 26.3\% [5.8], respectively; $P=.80$; Fig 3E). Details of the events in the randomized arms are shown in the Data Supplement. Censoring patients who received SCT or analysis by performed treatment instead of intention to treat (seven patients shifted from the experimental arm to the control arm) gave comparable results.

\section{Outcome by Patient Characteristics}

The 6-year EFS (SE) for KMT2A germline patients was 73.9\% (3.4) versus $36.4 \%$ (2.3) for KMT2A-rearranged patients ( $P<.001$; Data Supplement). t(4;11)- and t(11; 19)-rearranged cases seemed to have a lower 6 -year EFS than patients with a $t(9 ; 11)$ or other KMT2A translocations ( $P=.0052$; Data Supplement), but this finding was not confirmed by multivariate analysis (Tables 1 and 2). Younger age at diagnosis correlated with inferior outcome, with 6-year EFS of 25.1\% (3.9), 41.5\% (3.8), 49.0\% (4.0), and $68.1 \%$ (4.0) for patients age 0 to 3,3 to 6,6 to 9 , and 9 to 12 months, respectively $(P<.001)$, mainly because of differences in relapse rate (Data Supplement).

Patients with a WBC count of $300 \times 10^{9} / \mathrm{L}$ or greater had a 6 -year EFS of $24.5 \%$ (3.3) versus $41.0 \%$ (4.1) for those with WBC count of 100 to $300 \times 10 \% / L$ and $62.4 \%$ (2.9) for those with WBC less than $100 \times 10^{9} / \mathrm{L}$ at diagnosis $(P<$ .001; Data Supplement). CD10- B-lineage ALL had a lower 6-year EFS of $38.5 \%$ (2.6) than $\mathrm{CD}^{+} \mathrm{O}^{+} \mathrm{B}$-lineage $\mathrm{ALL}$ (57.7\% [3.6]; $P<.001$; Data Supplement). The 4-year EFS for biphenotypic ALL was 36.0\% (9.6), whereas it was 45.7\% (16.6) for T-cell ALL. Males had a slightly higher 6-year EFS (49.8\% [3.0]) than females (43.2\% [2.8]; $P=.032$; Data Supplement). Patients with a good response to prednisone had a better 6-year EFS (49.6\% [2.4]) than those with a poor response (31.9\% [4.1]; $P<.001$; Data Supplement).

On multivariate analysis, KMT2A status had the strongest prognostic value for EFS. Age and WBC at diagnosis and prednisone response remained of independent prognostic value, but CD10 status and sex did not (Table 1). Performing the multivariate analysis within the KMT2arearranged population resulted in the same conclusions (Table 2). An exploratory analysis looking for a more favorable subgroup of KMT2A-rearranged patients showed that infants age 9 months or older at diagnosis $(n=55)$ had a 6-year EFS of 61.9\% (SE, 6.8).

\section{Outcome by Country and Comparison of Interfant-06 Versus Interfant-99}

Outcome was better for patients treated in the original groups ( $n=447)$ than in the other countries $(n=204)$ : 6-year EFS probabilities were 49.4\% (2.5) versus 39.0\% (3.6; $P=.0018)$, and 6-year OS probabilities were $62.1 \%(2.4)$ versus $49.7 \%$ (3.7), respectively ( $P<.001$; Fig $4 A)$. This was due to differences in induction death $(2.2 \% \vee 6.9 \%)$, resistance to induction (2.9\% $\vee 4.4 \%)$, and death in remission (5.4\% $v 10.8 \%$ ); the relapse rate was comparable $(37.6 \% \vee 37.3 \%)$. Outcome for the original groups was also more favorable within risk groups: 6-year EFS for LR, MR, and $\mathrm{HR}$ was $77.8 \%$ (4.2), $49.0 \%$ (3.6), and $23.8 \%$ (4.2; Fig 2C), respectively, versus $66.4 \%$ (6.5), $35.4 \%$ (5.0), and $14.0 \%$ (5.3) for the other countries (Fig 2D). Analogous findings were observed for survival, with respective 6-year OS $91.2 \%(2.8), 62.5 \%$ (3.5), and $33.9 \%$ (4.7) versus $79.5 \%$ (5.5), 51.0\% (5.1), and $14.9 \%$ (5.6).

For the original groups there was no significant difference in 6-year EFS, (49.4\% [2.5] v 48.0\% [2.6]; $P=.73$ ) or 6-year OS (62.1\% [2.4] v 55.5\% [2.6]; $P=.20$ ) when comparing Interfant-06 to Interfant-99 (Fig 4B). There was also no significant difference in outcome for the other countries (6-year EFS, 39.0\% [3.6] v 40.0\% [5.3]; 6-year OS, 49.7\% [3.7] $\vee 46.1 \%$ [5.4]) when comparing Interfant-06 to Interfant-99. 


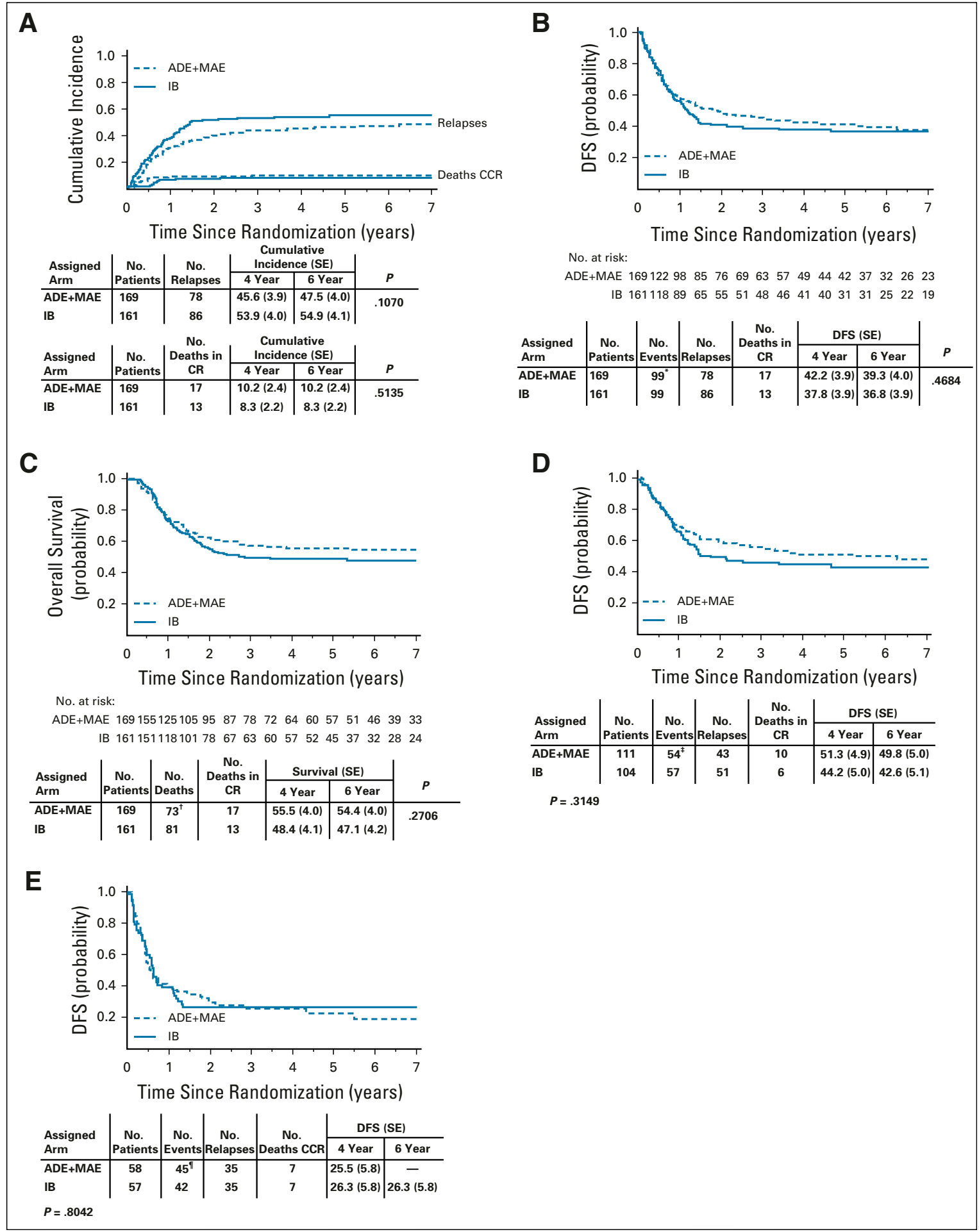

FIG 3. Outcome in Interfant-06 by randomized arm; low-dose cytosine arabinoside (araC), 6-mercaptopurine, cyclophosphamide (IB) versus araC, daunorubicin, etoposide (ADE) plus mitoxantrone, araC, etoposide (MAE). (A) Cumulative incidence of relapse and death in complete remission (CR) in Interfant-06 by randomized arm: IB versus ADE +MAE. (B) Disease-free survival (DFS) in Interfant-06 by randomized arm: IB versus $\mathrm{ADE}+\mathrm{MAE}$. ${ }^{*}$ ) Includes one death in induction and three second malignant neoplasms. (C) Overall survival in Interfant-06 by randomized arm: IB versus ADE+MAE. ( $\dagger$ ) Includes one death in induction. (D) DFS in Interfant-06 patients in medium-risk group by randomized arm: IB versus ADE + MAE. ( $\ddagger)$ Includes one second malignant neoplasm (post-transplantation Iymphoproliferative disorder after heart transplantation). (E) DFS in Interfant-06 patients in high-risk group by randomized arm: IB versus ADE+MAE. ( $\boldsymbol{( I ) ~ I n c l u d e s ~ o n e ~ d e a t h ~ i n ~ i n d u c t i o n ~ a n d ~ t w o ~ s e c o n d ~ m a l i g n a n t ~ n e o p l a s m s ~ ( n o n - H o d g k i n ~ l y m p h o m a ~ a n d ~}$ myelodysplastic syndrome). CCR, continuous complete remission. 
TABLE 1. Multivariate Analysis of Prognostic Factors in All Interfant-06 Cases

\begin{tabular}{llll} 
Variable & HR & 95\% Cl & $\boldsymbol{P}$ \\
\hline KMT2A status & 1 & & \\
\hline Germline & 2.73 & 1.79 to 4.17 & $<.001$ \\
\hline $\mathrm{t}(4 ; 11)+\mathrm{t}(11 ; 19)$ & 2.41 & 1.57 to 3.70 & $<.001$ \\
\hline $\mathrm{t}(9 ; 11)+$ other rearranged & & & \\
\hline Age at diagnosis, months & 1 & & \\
\hline$\geq 6$ & 1.57 & 1.23 to 2.00 & $<.001$ \\
\hline$<6$ & 1 & & \\
\hline WBC count at diagnosis, $\times 10^{9} / \mathrm{L}$ & & & \\
\hline$<300$ & 1.69 & 1.32 to 2.16 & $<.001$ \\
\hline$\geq 300$ & & & \\
\hline Prednisone response & 1 & & \\
\hline PGR & 1.53 & 1.18 to 1.99 & .0014 \\
\hline PPR & & & \\
\hline Immunophenotype & 1 & & \\
\hline B-lineage: CD10 & 1.05 & 0.83 to 1.33 & \\
\hline B-lineage: CD10 & & & \\
\hline Sex & 1.90254 & \\
\hline Male & & & \\
\hline Female & 1.54 & \\
\hline
\end{tabular}

NOTE. Analysis was done on 576 patients with available data.

Abbreviations: HR, hazard risk; PGR, prednisone good response; PPR, prednisone poor response.

\section{SCT}

The 6-year EFS of all 164 patients in the HR group was $20.9 \%$ (3.4), with the intention to perform transplantation in all patients in the HR group who reached CR $(n=143)$. Only 76 out of 143 received SCT, because many $(n=54)$ experienced an early event before SCT could be performed. Donor source included matched sibling donor in 10 , a matched unrelated donor in 54, and an HLA partially matched donor in 12 patients. Of the 76 patients undergoing transplantation, relapse occurred in 26 (34.2\%), 14 (18.4\%) died in CR from transplantation-related toxicity, and two developed a second malignancy, with a 4-year DFS after SCT of $44.0 \%$ (6.0).

From June 2009, SCT was recommended for patients in the MR group with MRD $10^{-4}$ or greater at the start of OCTADA(D). Out of 23 patients in the MR group with this MRD level, 16 received SCT; 4-year DFS after SCT was $18.8 \%$ (12.5), with four patients in continuous complete remission.

Of the total cohort, $18 \%$ of 605 patients in first complete remission (CR1) received SCT, namely 89 (21\%) of the 424 in CR1 in original groups and $22(12 \%)$ of the 181 patients in CR1 in other groups. A total of $14.4 \%$ of patients who underwent transplantation died as a result of SCT-related toxicity, without differences between the original and other
TABLE 2. Multivariate Analysis of Prognostic Factors in KMT2A-Rearranged Infant ALL Cases

\begin{tabular}{|c|c|c|c|}
\hline Variable & HR & $95 \% \mathrm{Cl}$ & $P$ \\
\hline \multicolumn{4}{|l|}{ KMT2A status } \\
\hline $\mathrm{t}(9 ; 11)+$ other rearranged & 1 & & \\
\hline $\mathrm{t}(4 ; 11)+\mathrm{t}(11 ; 19)$ & 1.21 & 0.86 to 1.47 & $<.4083$ \\
\hline \multicolumn{4}{|l|}{ Age at diagnosis, months } \\
\hline$\geq 6$ & 1 & & \\
\hline$<6$ & 1.75 & 1.34 to 2.28 & $<.001$ \\
\hline \multicolumn{4}{|c|}{ WBC count at diagnosis, $\times 10^{9} / \mathrm{L}$} \\
\hline$<300$ & 1 & & \\
\hline$\geq 300$ & 1.63 & 1.26 to 2.10 & $<.002$ \\
\hline \multicolumn{4}{|l|}{ Prednisone response } \\
\hline PGR & 1 & & \\
\hline PPR & 1.70 & 1.30 to 2.23 & $<.001$ \\
\hline \multicolumn{4}{|l|}{ Immunophenotype } \\
\hline B-lineage: CD10+ & 1 & & \\
\hline B-lineage: $\mathrm{CD}^{-} \mathrm{O}^{-}$ & 1.26 & 0.94 to 1.68 & .1166 \\
\hline \multicolumn{4}{|l|}{ Sex } \\
\hline Male & 1 & & \\
\hline Female & 1.05 & 0.82 to 1.34 & .6997 \\
\hline
\end{tabular}

NOTE. Analysis was done on 427 KMT2A-rearranged patients with available data.

Abbreviations: ALL, acute lymphoblastic leukemia; HR, hazard risk; PGR, prednisone good response; PPR, prednisone poor response.

countries. In 2006 to 2011, 13 of 50 (26\%) patients who underwent transplantation died in CR. The conditioning regimen was then changed from busulfan, cyclophosphamide, and melphalan into busulfan plus treosulfan, fludarabine, and thiotepa. In 2012 to 2016, three of 61 (5\%) died in CR after SCT.

\section{DISCUSSION}

This trial is the largest study for infant ALL. The OS rate of $62 \%$ in West European countries and North American institutes is $12 \%$ higher than in other countries, mainly because of fewer toxic deaths, illustrating how regional handling of this protocol influences outcome. Although Interfant-06 is of high intensity, it is less intense than the high-risk Berlin-Frankfurt-Muenster regimen, previously used in Europe for KMT2A-rearranged ALL, which included three high-risk chemotherapy courses. The 6 -year OS was $6 \%$ higher for patients treated in Interfant-06 compared with Interfant-99; however, this did not attain statistical significance. The Interfant-99 study resulted in a better outcome for infant ALL compared with outcome before 1999 in some of the national study groups. ${ }^{1}$ After that, outcome has not improved significantly by either Interfant or other cooperative groups, such as the Children's Oncology Group (COG). ${ }^{6}$ 

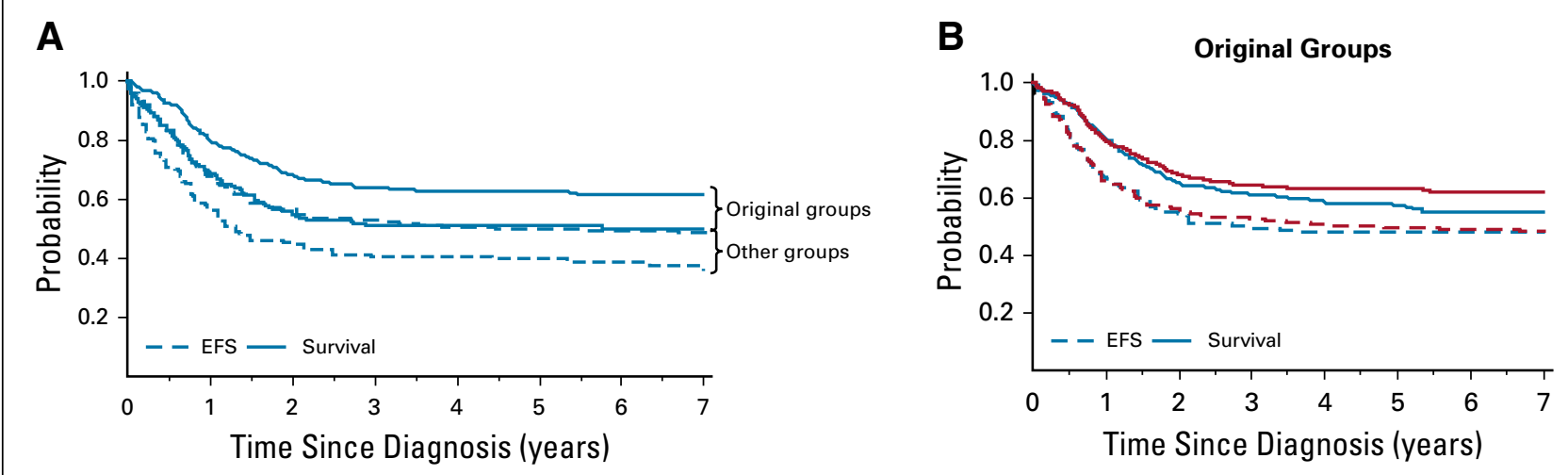

\begin{tabular}{|c|c|c|c|c|c|c|c|}
\hline & \multirow{2}{*}{$\begin{array}{c}\text { No. } \\
\text { Patients }\end{array}$} & \multirow{2}{*}{$\begin{array}{c}\text { No. Events } \\
\text { (relapses) }\end{array}$} & \multicolumn{2}{|c|}{ EFS (SE) } & \multirow{2}{*}{\begin{tabular}{|c|} 
No. \\
Deaths
\end{tabular}} & \multicolumn{2}{|c|}{ Survival (SE) } \\
\hline & & & 4 Year & 6 Year & & 4 Year & 6 Year \\
\hline $\begin{array}{l}\text { Original } \\
\text { groups }\end{array}$ & $\begin{array}{l}447 \\
69 \%\end{array}$ & 217 (168) & $50.9(2.4)$ & $49.4(2.5)$ & 159 & $63.0(2.4)$ & $62.1(2.4)$ \\
\hline $\begin{array}{l}\text { Other } \\
\text { groups }\end{array}$ & $\begin{array}{l}204 \\
31 \%\end{array}$ & $123(76)$ & $40.6(3.5)$ & $39.0(3.6)$ & 99 & $50.7(3.6)$ & $49.7(3.7)$ \\
\hline
\end{tabular}

Median follow-up (min-max), years: 5.3 (0.1-11.4)

Detailed overall outcome:

\begin{tabular}{|c|c|c|c|c|c|c|c|}
\hline & $\begin{array}{l}\text { Induction } \\
\text { Death }\end{array}$ & Resistant & Relapses & $\begin{array}{l}\text { Deaths } \\
\text { in CR }\end{array}$ & SMN & CCR & Total \\
\hline $\begin{array}{l}\text { Original } \\
\text { groups }\end{array}$ & $\begin{array}{c}10 \\
2.2 \%\end{array}$ & $\begin{array}{c}13 \\
2.9 \%\end{array}$ & $\begin{array}{c}168 \\
37.6 \%\end{array}$ & $\begin{array}{c}24 \\
5.4 \%\end{array}$ & $\begin{array}{c}2 \\
0.5 \%\end{array}$ & 230 & 447 \\
\hline $\begin{array}{l}\text { Other } \\
\text { groups }\end{array}$ & $\begin{array}{c}14 \\
6.9 \%\end{array}$ & $\begin{array}{c}9 \\
4.4 \%\end{array}$ & $\begin{array}{c}76 \\
37.3 \%\end{array}$ & $\begin{array}{c}22 \\
10.8 \%\end{array}$ & $\begin{array}{c}2 \\
1.0 \%\end{array}$ & 81 & 204 \\
\hline Total & 24 & 22 & 244 & 46 & 4 & 311 & 651 \\
\hline
\end{tabular}

\begin{tabular}{c|c|c|c|c|c}
\multicolumn{2}{c|}{ No. Patients (\%) } & \multicolumn{2}{c|}{ 6-Year EFS (SE) } & \multicolumn{2}{c}{ 6-Year Survival (SE) } \\
\hline Int99 & Int06 & Int99 & Int06 & Int99 & Int06 \\
\hline 388 & 447 & $48.0(2.6)$ & $49.4(2.5)$ & $55.5(2.6)$ & $62.1(2.4)$ \\
$81 \%$ & $69 \%$ & \multicolumn{2}{|c|}{$P=.73$} & \multicolumn{2}{|c}{$P=.20$}
\end{tabular}

Other Groups

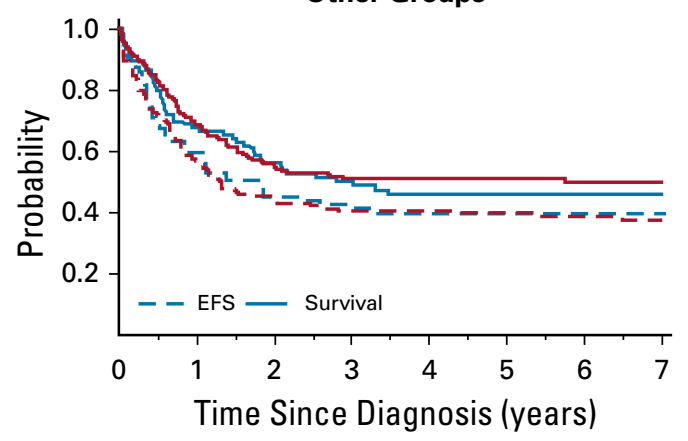

\begin{tabular}{c|c|c|c|c|c}
\multicolumn{2}{l|}{ No. Patients (\%) } & \multicolumn{2}{c|}{ 6-Year EFS (SE) } & \multicolumn{2}{c}{ 6-Year Survival (SE) } \\
\hline Int99 & Int06 & Int99 & Int06 & Int99 & Int06 \\
\hline 90 & 204 & $40.0(5.3)$ & $39.0(3.6)$ & $46.1(5.4)$ & $49.7(3.7)$ \\
$19 \%$ & $31 \%$ & \multicolumn{2}{|c|}{$P=.85$} & \multicolumn{2}{c}{$P=.69$}
\end{tabular}

FIG 4. Outcome by participating group in Interfant-06 (Int06) versus Interfant-99 (Int99). (A) Outcome by participating group in Interfant-06. Original groups refer to Western European Study groups and North American centers that founded Interfant (Associazione Italiana Ematologia Oncologia Pediatrica, Berlin-Frankfurt-Muenster Austria, Berlin-Frankfurt-Muenster Group Germany, German Cooperative Study Group for Childhood Acute Lymphoblastic Leukemia, Czech Working Group for Pediatric Hematology, Dutch Childhood Oncology Group, Dana Farber Cancer Institute, European Organisation for Research and Treatment of Cancer Children Leukemia Group, French Acute Lymphoblastic Leukemia Study Group, Nordic Society of Pediatric Hematology/Oncology, St Jude Children's Research Hospital, UK Children Cancer Study Group), and other groups are groups that joined Interfant later. (B) Outcome of Interfant-06 (red) versus Interfant-99. These groups represent Argentina, Chilean National Pediatric Oncology Group, Australian and New Zealand Childrens Haematology/Oncology Group, The Chinese University of Hong Kong, Polish Pediatric Leukemia/Lymphoma Study Group, and Seattle Children's Hospital and Research Institute. CCR, continuous complete remission; CR, complete remission; EFS, event-free survival; OS, overall survival; SMN, second malignant neoplasm.

The randomized use of two intensive myeloid-like chemotherapy courses did not lead to a statistically better outcome than the classic lymphoid-like course IB. The lower number of relapses with the myeloid-like courses was partly countered by more infectious deaths. The backbone of Interfant chemotherapy already contains low- and high-dose araC, the main component of AML therapy, and $180 \mathrm{mg} / \mathrm{m}^{2}$ anthracyclines. Our study shows that infant patients with ALL do not benefit from early intensification of therapy with additional araC and daunorubicin or from the other drugs, mitoxantrone and etoposide, as given in these AML-like courses.
The role of SCT for infant KMT2A-rearranged ALL is limited. ${ }^{7}$ The Japanese Pediatric Leukemia/Lymphoma Study Group previously applied SCT for all infant KMT2Arearranged ALL patients, whereas the COG eliminated SCT from treatment. ${ }^{8-10}$ In Interfant-99, SCT did not improve the outcome for patients in the MR group, ${ }^{1}$ but a small subgroup with HR infant ALL seemed to benefit from SCT. ${ }^{11}$ The current Interfant-06 study was not designed to compare SCT with chemotherapy. Approximately half of the patients in the HR group could not undergo transplantation in first CR because of an early 
event, mainly relapse; thus, patients undergoing transplantation represented a positively selected population. The 6-year EFS of all patients in the HR group was $21 \%$; for those who made it to transplantation, the 4-year DFS was $44 \%$. In 2009, eligibility for SCT was extended to patients in the MR group with MRD $10^{-4}$ or greater after mercaptopurine, Ara-C, and methotrexate, and asparaginase, because all these patients experienced relapse in Interfant 99. ${ }^{5}$ For these patients in the MR group who underwent SCT, the 4-year DFS was $19 \%$. So, still the far majority of these patients in the MR group relapsed despite the use of SCT. The toxic death rate related to SCT was $14 \%$ and did not differ between the original groups and the other countries. Together, these findings justify restricting the use of SCT for the select HR group that comprises only $25 \%$ of all KMT2A infant ALL cases. SCT can also be part of salvage therapy, with intensive chemotherapy plus SCT shown to cure $20 \%$ of patients who relapsed in Interfant-99. ${ }^{12}$

This study shows that the outcome of infant ALL with germline KMT2A (LR group) is favorable, with a 6 -year OS rate of $87 \%$ (Data Supplement). Infant ALL with germline KMT2A has a low incidence of the favorable ETV6/RUNX1 and hyperdiploid genetic subtypes, ${ }^{13-15}$, and thus treatment according to Interfant or to the schedules used for children age 1 year and older must be carefully balanced.

The current study confirms that KMT2A status is the strongest factor predicting outcome, followed by diagnosis, WBC count at diagnosis, and prednisone responses. ${ }^{16}$ It remains unclear as to why increasing age within infants is associated with a better outcome. ${ }^{13}$ We cannot exclude whether dose reductions in the young contribute to the inferior outcome of younger infants. However, the fact that older children with KMT2A-rearranged ALL have a better outcome compared with infants is also not understood. ${ }^{14}$

\footnotetext{
AFFILIATIONS

${ }^{1}$ Dutch Childhood Oncology Group, Utrecht, the Netherlands ${ }^{2}$ Princess Maxima Center for Pediatric Oncology, Utrecht, the Netherlands

${ }^{3}$ University of Milano-Bicocca, Monza, Italy

${ }^{4}$ United Kingdom Children Cancer Study Group, London, United Kingdom

${ }^{5}$ GATLA, Buenos Aires, Argentina

${ }^{6}$ French Acute Lymphoblastic Leukemia Study Group, Paris, France

${ }^{7}$ Istituto di Ricovero e Cura a Carattere Scientifico Bambino Gesù Children's Hospital, Rome, Italy

${ }^{8}$ University of Pavia, Pavia, Italy

${ }^{9}$ Chilean National Pediatric Oncology Group, Santiago, Chile

${ }^{10}$ German Cooperative Study Group for Childhood Acute Lymphoblastic Leukemia, Hamburg, Germany

${ }^{11}$ European Organisation for Research and Treatment of Cancer Children Leukemia Group, Brussels, Belgium

${ }^{12}$ Seattle Children's Hospital and Research Institute, Seattle, WA

${ }^{13}$ Australian and New Zealand Children's Haematology/Oncology Group Perth, Australia

${ }^{14}$ University of Western Australia, Perth, Western Australia, Australia

${ }^{15}$ Rigshospitalet, University of Copenhagen, Copenhagen, Denmark
}

The poor outcome of infant KMT2A-rearranged ALL requires more insight into its underlying biology. Successful inhibition of fms-like tyrosine kinase 3 in preclinical systems led to a clinical trial inhibiting this target, but without success. ${ }^{17-22} \mathrm{~A}$ subset of patients have subclonal rat sarcoma mutations, and mitogen-activated protein kinase kinase inhibitors have shown promising efficacy in preclinical models. ${ }^{23-27}$ Recently, preclinical research has focused on the abnormal epigenetic profile of KMT2Arearranged $A L^{28-33}$ and illustrated the potential of demethylating agents and histone deacetylase inhibitors. ${ }^{34-38}$ Immunotherapeutic approaches directed against B-cell antigens, such as those that are based on blinatumo$\mathrm{mab}^{39}$ and chimeric antigen receptor $\mathrm{T}$ cells, ${ }^{40}$ have shown high antileukemia potential in infant case reports. Lineage switch to myeloid leukemias has been reported under the pressure of such B-lineage-specific therapy; however, this switch can also be seen after standard chemotherapy against infant ALL. ${ }^{41-43}$ The COG and Interfant study groups are currently studying the safety and feasibility of adding azacitidine and blinatumomab to standard Interfant chemotherapy. If successful, the COG, Interfant, and Japanese Pediatric Leukemia/Lymphoma Study Group will collaborate globally to investigate these drugs further in the context of a worldwide randomized study.

In conclusion, the OS rate for infants with ALL in West European countries and North American institutes in Interfant06 is $62 \%$, which is $12 \%$ higher than in other participating countries. Early intensification with two postinduction AMLtype chemotherapy courses versus course IB did not lead to a significantly better outcome. Future studies will focus on the use of epigenetic drugs and immunotherapy on the Interfant backbone. ${ }^{6}$

\footnotetext{
${ }^{16}$ The Chinese University of Hong Kong, Shatin, Hong Kong, Special Administrative Region, People's Republic of China

${ }^{17}$ St Anna Children's Hospital, Medical University of Vienna, Vienna, Austria

${ }^{18}$ Children Cancer Research Institute, Vienna, Austria

${ }^{19}$ St Jude Children's Research Hospital, Memphis, TN

${ }^{20}$ Dana-Farber Cancer Institute, Boston, MA

${ }^{21}$ Czech Working Group for Pediatric Hematology, Prague, Czech Republic

${ }^{22}$ Polish Pediatric Leukemia/Lymphoma Study Group, Zabrze, Medical University of Silesia, Katowice, Poland

${ }^{23}$ Berlin-Frankfurt-Münster Group Germany, Kiel, Germany
}

\section{CORRESPONDING AUTHOR}

Rob Pieters, MD, PhD, MSc, Princess Máxima Center for Pediatric Oncology, Heidelberglaan 25, 3584 CS Utrecht, the Netherlands; e-mail: r.pieters@prinsesmaximacentrum.nl. 
AUTHORS' DISCLOSURES OF POTENTIAL CONFLICTS OF INTEREST AND DATA AVAILABILITY STATEMENT

Disclosures provided by the authors and data availability statement (if applicable) are available with this article at DOI https://doi.org/10.1200/ JCO.19.00261

\section{AUTHOR CONTRIBUTIONS}

Conception and design: Rob Pieters, Luis Alberto Aversa, Andrea Biondi, Gabriele Escherich, Franco Locatelli, Jeffrey E. Rubnitz, Lewis B. Silverman, Ajay Vora, Martin Schrappe, Maria Grazia Valsecchi Financial support: Rob Pieters

Administrative support: Rob Pieters

Provision of study material or patients: Rob Pieters, Gabriele Escherich, Alina Ferster, Rishi Sury Kotecha, Birgitte Lausen, Chi Kong Li, Lewis B. Silverman, Tomasz Szczepanski, Martin Schrappe
Collection and assembly of data: Rob Pieters, Paola De Lorenzo, Philip Ancliffe, Gabriele Escherich, Alina Ferster, Rebecca A. Gardner, Rishi Sury Kotecha, Birgitte Lausen, Chi Kong Li, Franco Locatelli, Andishe Attarbaschi, Christina Peters, Lewis B. Silverman, Jan Stary, Tomasz Szczepanski, Martin Schrappe, Maria Grazia Valsecchi

Data analysis and interpretation: Rob Pieters, Paola De Lorenzo, Philip Ancliffe, Benoit Brethon, Myriam Campbell, Rebecca A. Gardner, Rishi Sury Kotecha, Franco Locatelli, Tomasz Szczepanski, Ajay Vora, Martin Schrappe, Maria Grazia Valsecchi

Manuscript writing: All authors

Final approval of manuscript: All authors

Accountable for all aspects of the work: All authors

\section{REFERENCES}

1. Pieters R, Schrappe M, De Lorenzo P, et al: A treatment protocol for infants younger than 1 year with acute lymphoblastic leukaemia (Interfant-99): An observational study and a multicentre randomised trial. Lancet 370:240-250, 2007

2. Meyer C, Burmeister T, Gröger D, et al: The MLL recombinome of acute leukemias in 2017. Leukemia 32:273-284, 2018

3. Stam RW, den Boer ML, Meijerink JP, et al: Differential mRNA expression of Ara-C-metabolizing enzymes explains Ara-C sensitivity in MLL gene-rearranged infant acute lymphoblastic leukemia. Blood 101:1270-1276, 2003

4. Ramakers-van Woerden NL, Beverloo HB, Veerman AJ, et al: In vitro drug-resistance profile in infant acute lymphoblastic leukemia in relation to age, MLL rearrangements and immunophenotype. Leukemia 18:521-529, 2004

5. Van der Velden VH, Corral L, Valsecchi MG, et al: Prognostic significance of minimal residual disease in infants with acute lymphoblastic leukemia treated within the Interfant-99 protocol. Leukemia 23:1073-1079, 2009

6. Brown P, Pieters R, Biondi A: How I treat infant leukemia. Blood 133:205-214, 2019

7. Sison EA, Brown P: Does hematopoietic stem cell transplantation benefit infants with acute leukemia? Hematology (Am Soc Hematol Educ Program) 2013: 601-604, 2013

8. Tomizawa D, Koh $\mathrm{K}$, Sato $\mathrm{T}$, et al: Outcome of risk-based therapy for infant acute lymphoblastic leukemia with or without an MLL gene rearrangement, with emphasis on late effects: A final report of two consecutive studies, MLL96 and MLL98, of the Japan Infant Leukemia Study Group. Leukemia 21:2258-2263, 2007

9. Kosaka Y, Koh K, Kinukawa N, et al: Infant acute lymphoblastic leukemia with MLL gene rearrangements: outcome following intensive chemotherapy and hematopoietic stem cell transplantation. Blood 104:3527-3534, 2004

10. Dreyer ZE, Dinndorf PA, Camitta B, et al: Analysis of the role of hematopoietic stem-cell transplantation in infants with acute lymphoblastic leukemia in first remission and MLL gene rearrangements: A report from the Children's Oncology Group. J Clin Oncol 29:214-222, 2011

11. Mann G, Attarbaschi A, Schrappe M, et al: Improved outcome with hematopoietic stem cell transplantation in a poor prognostic subgroup of infants with mixedlineage-leukemia (MLL)-rearranged acute lymphoblastic leukemia: Results from the Interfant-99 Study. Blood 116:2644-2650, 2010

12. Driessen $\mathrm{EM}$, de Lorenzo $\mathrm{P}$, Campbell $\mathrm{M}$, et al: Outcome of relapsed infant acute lymphoblastic leukemia treated on the interfant-99 protocol. Leukemia 30 : 1184-1187, 2016

13. van der Linden MH, Boer JM, Schneider P, et al: Clinical and molecular genetic characterization of wild-type MLL infant acute lymphoblastic leukemia identifies few recurrent abnormalities. Haematologica 101:e95-e98, 2016

14. De Lorenzo P, Moorman AV, Pieters R, et al: Cytogenetics and outcome of infants with acute lymphoblastic leukemia and absence of MLL rearrangements. Leukemia 28:428-430, 2014

15. Nagayama J, Tomizawa D, Koh K, et al: Infants with acute lymphoblastic leukemia and a germline MLL gene are highly curable with use of chemotherapy alone: Results from the Japan Infant Leukemia Study Group. Blood 107:4663-4665, 2006

16. Biondi A, Cimino G, Pieters R, et al: Biological and therapeutic aspects of infant leukemia. Blood 96:24-33, 2000

17. Pui $\mathrm{CH}$, Gaynon PS, Boyett JM, et al: Outcome of treatment in childhood acute lymphoblastic leukaemia with rearrangements of the $11 \mathrm{q} 23$ chromosomal region. Lancet 359:1909-1915, 2002

18. Armstrong SA, Kung AL, Mabon ME, et al: Inhibition of FLT3 in MLL. Validation of a therapeutic target identified by gene expression based classification. Cancer Cell 3:173-183, 2003

19. Brown P, Levis M, McIntyre E, et al: Combinations of the FLT3 inhibitor CEP-701 and chemotherapy synergistically kill infant and childhood MLL-rearranged ALL cells in a sequence-dependent manner. Leukemia 20:1368-1376, 2006

20. Stam RW, den Boer ML, Schneider P, et al: Targeting FLT3 in primary MLL-gene-rearranged infant acute lymphoblastic leukemia. Blood 106:2484-2490, 2005

21. Brown P, Levis M, Shurtleff S, et al: FLT3 inhibition selectively kills childhood acute lymphoblastic leukemia cells with high levels of FLT3 expression. Blood 105: 812-820, 2005

22. Stam RW, Schneider P, de Lorenzo P, et al: Prognostic significance of high-level FLT3 expression in MLL-rearranged infant acute lymphoblastic leukemia. Blood 110:2774-2775, 2007

23. Driessen EM, van Roon EH, Spijkers-Hagelstein JA, et al: Frequencies and prognostic impact of RAS mutations in MLL-rearranged acute lymphoblastic leukemia in infants. Haematologica 98:937-944, 2013

24. Emerenciano M, Barbosa TC, de Almeida Lopes B, et al: Subclonality and prenatal origin of RAS mutations in KMT2A (MLL)-rearranged infant acute lymphoblastic leukaemia. Br J Haematol 170:268-271, 2015 
25. Trentin L, Bresolin S, Giarin E, et al: Deciphering KRAS and NRAS mutated clone dynamics in MLL-AF4 paediatric leukaemia by ultra deep sequencing analysis. Sci Rep 6:34449, 2016

26. Kerstjens M, Driessen EM, Willekes M, et al: MEK inhibition is a promising therapeutic strategy for MLL-rearranged infant acute lymphoblastic leukemia patients carrying RAS mutations. Oncotarget 8:14835-14846, 2017

27. Kerstjens M, Pinhancos SS, Castro PG, et al: Trametinib inhibits RAS-mutant MLL-rearranged acute lymphoblastic leukemia at specific niche sites and reduces ERK phosphorylation in vivo. Haematologica 103:e147-e150, 2018

28. Kang H, Wilson CS, Harvey RC, et al: Gene expression profiles predictive of outcome and age in infant acute lymphoblastic leukemia: A Children's Oncology Group study. Blood 119:1872-1881, 2012

29. Stam RW, Schneider P, Hagelstein JA, et al: Gene expression profiling-based dissection of MLL translocated and MLL germline acute lymphoblastic leukemia in infants. Blood 115:2835-2844, 2010

30. Armstrong SA, Staunton JE, Silverman LB, et al: MLL translocations specify a distinct gene expression profile that distinguishes a unique leukemia. Nat Genet 30:41-47, 2002

31. Schafer E, Irizarry R, Negi S, et al: Promoter hypermethylation in MLL-r infant acute lymphoblastic leukemia: Biology and therapeutic targeting. Blood 115: 4798-4809, 2010

32. Stumpel DJ, Schneider P, van Roon EH, et al: Specific promoter methylation identifies different subgroups of MLL-rearranged infant acute lymphoblastic leukemia, influences clinical outcome, and provides therapeutic options. Blood 114:5490-5498, 2009

33. Stumpel DJ, Schneider P, van Roon EH, et al: Absence of global hypomethylation in promoter hypermethylated Mixed Lineage Leukaemia-rearranged infant acute lymphoblastic leukaemia. Eur J Cancer 49:175-184, 2013

34. Bhatla T, Wang J, Morrison DJ, et al: Epigenetic reprogramming reverses the relapse-specific gene expression signature and restores chemosensitivity in childhood B-lymphoblastic leukemia. Blood 119:5201-5210, 2012

35. Garrido Castro P, van Roon EHJ, Pinhanços SS, et al: The HDAC inhibitor panobinostat (LBH589) exerts in vivo anti-leukaemic activity against MLL-rearranged acute lymphoblastic leukaemia and involves the RNF20/RNF40/WAC-H2B ubiquitination axis. Leukemia 32:323-331, 2018

36. Stumpel DJ, Schneider P, Seslija L, et al: Connectivity mapping identifies HDAC inhibitors for the treatment of $t(4 ; 11)$-positive infant acute lymphoblastic leukemia. Leukemia 26:682-692, 2012

37. Burke MJ, Brown P, Gore L: Invasive Candida infections in pediatric patients treated on the pilot study of decitabine and vorinostat with chemotherapy for relapsed ALL: A report from the therapeutic advances in childhood leukemia \& lymphoma (TACL) Consortium. Blood 124:3650, 2014

38. Cruickshank MN, Ford J, Cheung LC, et al: Systematic chemical and molecular profiling of MLL-rearranged infant acute lymphoblastic leukemia reveals efficacy of romidepsin. Leukemia 31:40-50, 2017

39. von Stackelberg A, Locatelli F, Zugmaier G, et al: Phase I/phase II study of blinatumomab in pediatric patients with relapsed/refractory acute lymphoblastic leukemia. J Clin Oncol 34:4381-4389, 2016

40. Maude SL, Laetsch TW, Buechner J, et al: Tisagenlecleucel in children and young adults with B-Cell lymphoblastic leukemia. N Engl J Med 378:439-448, 2018

41. Rayes A, McMasters RL, O'Brien MM: Lineage switch in MLL-rearranged infant leukemia following CD19-directed therapy. Pediatr Blood Cancer 63: 1113-1115, 2016

42. Mejstríková E, Hrusak O, Borowitz MJ, et al: CD19-negative relapse of pediatric B-cell precursor acute lymphoblastic leukemia following blinatumomab treatment. Blood Cancer J 7:659, 2017

43. Gardner R, Wu D, Cherian S, et al: Acquisition of a CD19-negative myeloid phenotype allows immune escape of MLL-rearranged B-ALL from CD19 CAR-T-cell therapy. Blood 127:2406-2410, 2016 
Outcome of Infants Younger Than 1 Year With Acute Lymphoblastic Leukemia Treated With the Interfant-06 Protocol: Results From an International Phase III Randomized Study

The following represents disclosure information provided by authors of this manuscript. All relationships are considered compensated. Relationships are self-held unless noted. I = Immediate Family Member, Inst = My Institution. Relationships may not relate to the subject matter of this manuscript. For more information about ASCO's conflict of interest policy, please refer to www.asco.org/rwc or ascopubs.org/jco/site/ifc.

\section{Rob Pieters}

Honoraria: ERYTECH Pharma, Jazz Pharmaceuticals, Kite Pharma Consulting or Advisory Role: ERYTECH Pharma, Kite Pharma, Jazz Pharmaceuticals, Servier

Travel, Accommodations, Expenses: ERYTECH Pharma, Kite Pharma, Jazz Pharmaceuticals, Servier

Luis Alberto Aversa

Employment: CSL Behring Argentina

Benoit Brethon

Honoraria: Amgen SAS, Jazz Pharmaceutical

Consulting or Advisory Role: Amgen SAS

Travel, Accommodations, Expenses: Amgen SAS

Andrea Biondi

Consulting or Advisory Role: Novartis, Celgene

Rebecca A. Gardner

Honoraria: Novartis

Travel, Accommodations, Expenses: Novartis

Rishi Sury Kotecha

Travel, Accommodations, Expenses: Novartis

Chi Kong Li

Consulting or Advisory Role: Amgen Asia

Franco Locatelli

Honoraria: Bellicum Pharmaceuticals, Miltenyi Biotec, Bluebird Bio Consulting or Advisory Role: Amgen, Novartis

Andishe Attarbaschi

Honoraria: Jazz Pharmaceuticals, Amgen

Consulting or Advisory Role: Jazz Pharmaceuticals, Amgen

Travel, Accommodations, Expenses: Jazz Pharmaceuticals

\section{Christina Peters}

Honoraria: Neovii Biotech, Jazz Pharmaceuticals, Novartis Consulting or Advisory Role: Amgen, Neovii Biotech

Speakers' Bureau: Medac, Riemser

Research Funding: Medac (Inst), Neovii Biotech (Inst), Riemser (Inst)

Travel, Accommodations, Expenses: Neovii Biotech, Jazz Pharmaceuticals

Lewis B. Silverman

Consulting or Advisory Role: Adaptive Biotechnologies, Takeda, Servier Research Funding: Baxalta/Shire (Inst)

Research Funding: Servier (Inst)

Tomasz Szczepanski

Consulting or Advisory Role: Roche, Jazz Pharmaceuticals, Novartis Speakers' Bureau: Takeda, Nutricia

Travel, Accommodations, Expenses: Jazz Pharmaceuticals, Takeda, Pfizer, Gilead Sciences, CSL Behring, Octapharma, Amgen, Novartis

\section{Ajay Vora}

Consulting or Advisory Role: Jazz Pharmaceuticals, Pfizer, Medac, Amgen, Janssen Oncology, Novartis Pharmaceuticals UK

Travel, Accommodations, Expenses: Medac

Martin Schrappe

Consulting or Advisory Role: Novartis, Servier, Jazz Pharmaceuticals Research Funding: Shire (Inst), Novartis (Inst), Servier Travel, Accommodations, Expenses: Jazz Pharmaceuticals, Servier

No other potential conflicts of interest were reported. 